\title{
Memórias manchadas e ruínas memoriais em A mancha e "O condomínio", de Luis Fernando Veríssimo
}

Leila Lehnen $^{1}$

Em junho de 2012, uma amiga e colega, cuja pesquisa foca questões de construção de memória e justiça de transição, veio me visitar em Porto Alegre. A ideia era explorar os memoriais às vítimas do regime militar na cidade. ${ }^{2}$ Nosso primeiro destino foi o Memorial aos Mortos e Desaparecidos, localizado no Parque Marinha do Brasil. O parque é muito frequentado pelos porto-alegrenses, especialmente nos fins de semana. Depois de andarmos pelo parque, perguntando a várias pessoas sobre a localização do monumento, sem muito êxito - ninguém parecia saber do que estávamos falando -, finalmente o encontramos. Localizado numa esquina pouco frequentada por passeantes, dando as costas ao parque e ao mesmo tempo visível desde a movimentada avenida Beira-Rio, o Memorial aos Mortos e Desaparecidos é, assim, tanto altamente visível como invisível (figura 1). ${ }^{3}$ Talvez por causa dessa localização como que esquizofrênica, o monumento, inaugurado em 1995, é desconhecido pela maioria dos frequentadores do parque. Seu estado de deterioração (e alguns dos usos que os transeuntes fazem dele $)^{4}$ indica não somente o desconhecimento da sua presença no parque mas também a ignorância a respeito do seu significado.

O memorial, uma estrutura geométrica de metal desenhada pelo artista gaúcho Luiz Gonzaga, tem os nomes dos desaparecidos gravados na parte de trás da estrutura (figura 2), que dá a uma área com arbustos e árvores. Os nomes das vítimas da ditadura estão sendo lentamente apagados pela ferrugem. A parte dianteira, originalmente uma superfície lisa de metal, agora tem várias pichações (nenhuma delas alude à ditadura). Em outras palavras, a menos que o visitante saiba de que trata o monumento, este carece de sentido. A inscrição dos nomes

\footnotetext{
${ }^{1}$ Doutora em literatura espanhola e brasileira e professora de literatura brasileira na University of New Mexico, Albuquerque, Estados Unidos. E-mail: llehnen@unm.edu

${ }^{2}$ Agradeço a inspiração e as valiosas observações e comentários feitos por Rebecca Atencio sobre o ensaio.

${ }^{3}$ As fotos incluídas ao final deste texto são cortesia de Arno Carlos Lehnen.

${ }^{4}$ A parte de trás do monumento aparenta ser frequentemente usada como mictório.
} 
dos desaparecidos na parte de trás é uma escolha estranha para um monumento cuja função é "manter viva a memória dos fatos", segundo inscrição no próprio memorial. Na sua visibilidade e invisibilidade paralelas, o monumento exemplifica como, apesar da sua evidência (ou seja, a de uma estrutura de tamanho respeitável, localizada em um espaço público transitado), as vítimas da ditadura militar de 1964-1985 em grande parte despareceram da memória pública após a transição democrática.

O segundo destino da nossa excursão foi o antigo Departamento de Ordem Política e Social, que fica na avenida João Pessoa, 2050. Apenas recentemente esse edifício foi identificado oficialmente com a ditadura militar. Em 2012, o antigo DOPS - assim como outros lugares em e perto de Porto Alegre, tais como a ilha das Pedras Brancas, mais conhecida como a "ilha do Presídio" - deveria ter recebido uma placa com a inscrição "Aqui houve tortura". ${ }^{5}$ Durante a ditadura, várias pessoas, consideradas "dissidentes" pelo regime foram interrogadas e por vezes torturadas nas dependências do DOPS. Mas, quando perguntamos aos funcionários na recepção sobre qualquer informação que pudessem ter a respeito do passado do edifício em que nos encontrávamos, eles pareciam não saber dessa parte infame da história do prédio. E eles também não sabiam nada a respeito de uma placa comemorativa reconhecendo o passado violento do lugar. Embora os funcionários tivessem ouvido rumores sobre violações de direitos humanos durante a ditadura, eles não necessariamente associavam esse edifício - ligado ao cumprimento da lei - a ditos abusos. No entanto, os funcionários na recepção tinham ouvido falar de outro lugar onde o DOPS tinha conduzido tortura e interrogatórios. Essa informação pareceu uma estranha forma de transferência, em que a localização de abusos cometidos no passado (ou seja, durante a ditadura) é mudada de um local a outro, transferindo assim, de certa forma, a responsabilidade por essas violações. Essa transferência sugere-nos uma forma de amnésia institucional que põe a responsabilidade das violações de direitos

\footnotetext{
${ }^{5}$ As placas são parte do projeto Marcas da Memória, que deve identificar lugares em Porto Alegre onde o regime militar praticou a repressão. As placas serão colocadas na frente desses lugares e deverão oferecer uma breve história do que aconteceu ali durante a ditadura. Entre esses locais está o Palácio da Polícia Civil, a ilha do Presídio e o cais da praça Mauá, onde os prisioneiros embarcavam rumo à ilha. Também o Dopinha na rua Santo Antônio e o antigo quartel da polícia militar na praça Argentina devem receber as placas. O projeto é uma colaboração entre a cidade de Porto Alegre e o Movimento de Justiça e Direitos Humanos (MJDH).
} 
humanos em um passado remoto, absolvendo os atores institucionais no presente de qualquer culpabilidade por essas ações.

Seguindo as indicações dos funcionários no Palácio da Polícia Civil, fomos até um casarão da virada do século, na rua Santo Antônio 600, no bairro Bom Fim (figura 3), uma rua residencial de classe média. Durante a ditadura, essa casa era conhecida como "Dopinha". O casarão, rodeado de prédios, estava à venda. No passado recente a casa foi uma clínica infantil, além de ter abrigado outros negócios (Mitchell, 2007). Em 1964, o coronel Luiz Menna Barreto estabeleceu aqui uma filial clandestina do DOPS em Porto Alegre. O Dopinha esteve em operação até 1966, tendo sido fechado após a morte de Manoel Raymundo Soares, membro do Movimento Revolucionário 26 de Março, que foi detido e torturado nesse lugar. Em março de 2013, a cidade de Porto Alegre decidiu expropriar a casa para transformá-la em um museu dedicado à memória das vítimas da ditadura. O museu deve levar o nome do militante do VAR-Palmares e da Aliança Libertadora Nacional Luiz Eurico Tejera Lisbôa, desaparecido em 1972.

Em junho de 2012 o único indício do passado sombrio do casarão era um cartaz rasgado que indicava a importância histórica do lugar. Algumas semanas antes, em maio de 2012, o Comitê Carlos de Ré organizou uma manifestação em frente ao número 600 da rua Santo Antônio, exigindo justiça para as vítimas do regime militar. Um dos objetivos do evento era que fosse criado no local um Centro de Memória Viva da Resistência Latino Americana. O cartaz, assim como dizeres pedindo justiça para as vítimas da ditadura que estavam afixados às paredes do casarão, eram sobras dos protestos. Mas nada mais sugeria a história nefanda da casa na rua Santo Antônio.

Esses três locais são alguns exemplos de espaços que são repositórios de memórias traumáticas. ${ }^{6}$ São lugares que representam - de forma material - a violência de estado que assolou vários países do Cone Sul entre meados dos anos 60 e princípios de 90, incluindo o Brasil entre 1964-1985. Alguns, como o Dopinha e o Memorial da Resistência, na cidade de São Paulo, são lugares em que a ditadura literal e metaforicamente inscreveu uma memória infausta em paredes, tetos, portas e porões.

${ }^{6}$ Entre estes podemos incluir o antigo prédio do DOPS, em São Paulo, que agora é sede do Memorial da Resistência. 
Memoriais - sejam estes construídos de forma consciente, como o monumento Tortura Nunca Mais, criado por Demetrio Albuquerque e localizado no Recife, ou lugares "encontrados", transformados em memoriais pelo significado que adquiriram pelo seu uso, como o Dopinha em Porto Alegre - são estruturas que "comemoram o passado reconhecendo sacrifícios e perdas" (Hite, 2007, p. 7). Memoriais podem ajudar no processo coletivo - e público - da memória. Idealmente, a presença física de estruturas como estátuas, placas, edifícios vai inspirar o visitante ou o transeunte a lembrar ou a refletir sobre seu significado. De certa forma, os memoriais referidos são histórias que ajudam na "luta pela superação das violências perpetradas ao longo destes anos (da ditadura) e reforçam o compromisso do Estado e da sociedade com os valores democráticos" (Comitê Carlos de Ré, s/d). Monumentos e outras iniciativas que promovem o "trabalho da memória" (Jelin et al., 2003), tais como obras literárias, composições musicais, filmes, entre outros, cumprem duas funções. Uma é resgatar o passado através do ato de recordar. A outra é dirigida ao futuro no sentido que essas ações podem fortalecer a sociedade civil e a cultura democrática.

Não obstante, como todas as narrativas, as histórias que os monumentos e memoriais contam não têm apenas um sentido. A pesquisadora da memória Elizabeth Jelin observa que as conotações dessas estruturas podem mudar de acordo com quem as visita/observa. Por outro lado, o significado de monumentos e memoriais também muda conforme a realidade social, política e histórica. Dessa forma, ao passo que monumentos e memoriais são criados para evocar memórias, eles podem, paradoxalmente, representar justamente a perda de uma memória (histórica, social, cultural).

O que chama a atenção de marcos históricos tais como o Memorial aos Mortos e Desaparecidos em Porto Alegre e o Dopinha é - pelo menos até recentemente - sua (quase) obscuridade, a supressão do seu passado penoso. Tanto o Dopinha como outro famoso centro de tortura, a chamada "Casa da Morte", em Petrópolis (RJ), são exemplos dessa perda de memória histórica. Assim como a ditadura gravou uma narrativa violenta nas paredes dessas duas casas, após a transição os residentes das duas moradas escreveram a história de suas vidas cotidianas em cima da narrativa de horror que antecedeu essa vida cotidiana. Em 1978, por exemplo, a família de Renato Firmento de Noronha comprou a Casa da Morte em Petrópolis, lá residindo até que 
o domicílio fosse expropriado pela prefeitura em 2012 com o objetivo de transformar o lugar em um museu. A família Noronha vê na Casa da Morte um lar e se opõe à sua conversão em um museu. Para eles, a história violenta da casa foi reescrita, como se fosse um palimpsesto, por sua própria narrativa de churrascos nos fins de semana e de crianças brincando no quintal:

O quarto de onde o menino (o filho de Renato Noronha) contemplava a serra ao acordar é o mesmo onde Inês (Etienne) convalesceu por 40 dias do atropelamento sofrido durante sua captura, até estar em condições de ser torturada. A cozinha onde ela era obrigada a preparar nua a comida de seus algozes serviria também à inesquecível lasanha que Renato preparava para os filhos e sobrinhos nos domingos. O quarto que hoje acolhe a simpática empregada do engenheiro é aquele onde militares aplicavam choques elétricos e pentatol sódico, o soro da verdade, nos interrogatórios da guerrilheira (Marsiglia, 2012).

A justaposição entre as rotinas diárias da família e o horror da tortura e da morte violenta aponta à coexistência esquizofrênica do passado. Esquizofrênica, porque os limites entre diferentes versões/experiências do passado são tênues e, dessa forma, se confundem. Tanto a Casa da Morte, como o Dopinha, são locais esquizofrênicos da memória, onde esta é reescrita como se ditos lugares fossem um palimpsesto. Aqui a história individual/familiar é composta em cima da história pública, as rotinas do dia a dia são inscritas sobre as rotinas da violência de estado e diferentes camadas do passado se mesclam e confundem as memórias do passado ditatorial no país.

Se, de acordo com a Emenda Constitucional no 7.037, de 21 de dezembro de 2009, o direito à memória e à verdade é reconhecido como um "Direito Humano da cidadania e dever do Estado", na diretriz no 23 do Plano Nacional de Direitos Humanos 3, o chamado "PNDH-3", então o que significa o acesso à memória para o exercício da cidadania no Brasil?

Este ensaio propõe que locais esquizofrênicos da memória construídos como palimpsestos de várias (e muitas vezes contraditórias) versões do passado - estão conectados com o que o antropólogo James Holston (2008) denomina de "cidadania diferenciada". Se o "direito à memória e à verdade" é uma parte integral da cidadania, e sua proteção é um dever do estado, então as memórias disjuntivas, conflitivas e 
incompletas da ditadura militar, resultado em parte do silenciar proposital dos abusos cometidos durante o regime, violam um direito básico da cidadania. Disposições legais tais como a Lei da Anistia de 1979 também infringem o direito constitucional à memória e à verdade. Tais disposições evidenciam uma discrepância entre os direitos formais e substantivos da memória e, por isso, da cidadania, sendo assim um exemplo da cidadania diferenciada. Este artigo estabelece uma analogia entre os direitos diferenciados da memória e as disposições constitucionais que legalizam as diferenças sociais e civis e que, segundo Holston, são uma das características da cidadania diferenciada. ${ }^{7}$

Holston propõe que a cidadania diferenciada é central à composição política, social e civil do Brasil. Esse tipo de cidadania é um produto do que ele denomina de "democracia disjuntiva" ${ }^{8}$ Através da análise de uma novela, A mancha, e de um conto, "O condomínio", ambos do escritor gaúcho Luis Fernando Veríssimo, este ensaio ilustrará como direitos diferenciados à memória existem em conjunção com expressões de cidadania diferenciada.

Os dois textos de Luis Fernando Veríssimo fazem uma representação dos acima mencionados locais esquizofrênicos da memória. Esses lugares, repositórios de histórias contraditórias, promovem tanto a atividade mnemônica como a amnésia. Ambos os textos de Veríssimo demonstram como as memórias esquizofrênicas, produto de direitos diferenciados à memória, contribuem para a expressão da cidadania diferenciada. Seguindo a ordem cronológica da publicação dos textos, primeiro se discutirá “O condomínio" e depois se examinará A mancha.

\section{"O condomínio"}

Ao abordar a importância do "trabalho da memória" após períodos de repressão política, Elizabeth Jelin (2003) sintetiza a importância desse exercício. Escreve Jelin: "No âmbito coletivo, o grande desafio é o de

\footnotetext{
${ }^{7}$ Uma expressão da cidadania diferenciada é a disposição legal que permite que cidadãos brasileiros com diploma universitário tenham direito à prisão especial no caso de prisões provisórias, portanto antes do julgamento definitivo. Ao mesmo tempo a constituição declara que todos os brasileiros são iguais perante a lei.

${ }^{8}$ As democracias disjuntivas são, de acordo com Holston (2008, p. 77), sistema políticos democráticos que no entanto apresentam falhas no que tange os direitos civis e que muitas vezes apresentam direitos sociais frágeis ou insuficientes.
} 
evitar repetições, de transpor silêncios e abusos políticos, de ser capaz de simultaneamente se distanciar de, e promover, um debate ativo e uma reflexão sobre o passado e o seu significado para o presente/futuro" (Jelin et al., 2003, p. 7). "O condomínio", de Luis Fernando Veríssimo, publicado em 1982, três anos antes da transição democrática, indaga sobre o que acontece com memórias traumáticas em um contexto em que a vítima e o algoz têm que coexistir e em que o trabalho da memória é dissuadido. O conto, portanto, prevê a conjuntura sociopolítica da transição democrática.

Iniciada pelas autoridades militares, a "distensão" ("lenta, gradual e segura") não abriu um espaço para a discussão do registro de violações de direitos humanos da ditadura. O governo de José Sarney, um exintegrante da Arena - Aliança Renovadora Nacional -, tampouco tentou lidar com o legado do regime militar. Ainda que o sucessor de Sarney, Fernando Collor de Mello, tenha aberto alguns dos arquivos da ditadura, foi somente em 1995, durante a presidência de Fernando Henrique Cardoso, que o estado brasileiro finalmente reconheceu alguns dos abusos cometidos durante a ditadura, tomando assim os primeiros passos no processo de reparações.

A Lei no 9.140, a Lei dos Desaparecidos Políticos, outorga compensação monetária aos familiares de pessoas desaparecidas pela ação do estado durante o período 1961-1976. Inicialmente a lei beneficiou os familiares de 136 desparecidos políticos. No entanto, o artigo 2 da lei estipula que esta será aplicada de acordo com o "princípio de reconciliação e de pacificação nacional, expresso na Lei no 6.683 de 28 de agosto de 1979".

Coincidentemente, a Lei dos Desparecidos Políticos cobre os mesmos anos que a Lei da Anistia, sugerindo assim a impunidade das violações de direitos humanos cometidos entre 1961-1976 (Cano e Ferreira, 2006). ${ }^{9}$ Ainda que o governo democrático de Fernando Henrique Cardoso reconhecesse que os direitos humanos tivessem sido infringidos pela ditadura militar, ele (sua administração) continuou aceitando os parâmetros estipulados pela Lei da Anistia - em nome da reconciliação nacional. Nesse contexto, outras medidas para promover a justiça de

\footnotetext{
${ }^{9}$ Lei $\mathrm{n}^{\mathrm{o}}$ 10.536/02, de 2002, mudou o período de tempo para incluir o período entre o 2 de setembro de 1961 e o 5 de outubro de 1988.
} 
transição ${ }^{10}$ estavam fora de questão. Kathryn Sikkink (2011, p. 144) observa que o caso do Brasil é único no que se refere à justiça de transição, pois substitui o processo legal por reparações monetárias.

A Lei da Anistia foi o resultado de esforços de familiares de vítimas da repressão e contou com amplo apoio da população brasileira (Mezarobba, 2010). A lei perdoa àqueles que "no período compreendido entre 2 de setembro de 1961 e 15 de agosto de 1979, cometeram crimes políticos ou conexo com estes, crimes eleitorais" (Brasil, 1979, art. 1o). "Crimes políticos" são entendidos nesse contexto como transgressões incididas tanto pelos opositores do regime como também por agentes de estado. Todavia, algumas contravenções não são cobertas pela lei. $\mathrm{O}$ artigo 2 da lei declara que a anistia não cobre indivíduos que "foram condenados pela prática de crimes de terrorismo, assalto, sequestro e atentado pessoal".

Os dois artigos destacam a disparidade legal entre atores do estado e membros da resistência armada, que (pelo menos ao nível retórico) não se beneficiam da anistia. Enquanto os primeiros recebem perdão incondicional pelas violações contra os direitos humanos cometidos durante o regime militar, os segundos - se culpados de "terrorismo", roubo, sequestro, e "atentados pessoais" - não se beneficiam dessa exoneração, embora seus atos possam ser considerados como justificados na luta contra a tirania e opressão (Preâmbulo da Declaração Universal dos Direitos Humanos). Adicionalmente, na sua versão inicial, a Lei da Anistia não beneficiou todos os exilados políticos. A lei tampouco compensava aqueles que haviam perdido empregos por causa da repressão (Cano e Ferreira, 2006). ${ }^{11}$ Ou seja, na sua versão original, a Lei da Anistia beneficiava principalmente os agentes do estado repressor. Glenda Mezarobba defende que, em 1997, a Lei da Anistia queria proteger esses agentes de possíveis processos legais por abusos de direitos humanos cometidos durante a ditadura. A lei era vista como a expressão da "anistia como esquecimento e impunidade" (Abrão e Torelly, 2012, p. 152).

\footnotetext{
${ }^{10}$ De acordo com Ruti Teitel, a justiça de transição necessariamente implica uma dimensão jurídica. Segundo Teitel, "a concepção de justiça associada a períodos de mudança política, é caracterizada por respostas legais que confrontam os abusos cometidos por regimes opressivos anteriores" (Teitel, 2000, p. 69).

${ }^{11}$ Como indicam Paulo Abrão e Marcelo D. Torelly (2012), o processo de transição viu a implementação de leis que retificam estas omissões.
} 
Como resultado, a Lei da Anistia, pelo menos inicialmente, também encorajou o silêncio por parte de grande parte do público brasileiro sobre os crimes contra os direitos humanos cometidos durante regime militar. Ao outorgar um perdão (ainda que teoricamente parcial) a ambos os lados do conflito, a Lei no 6.683 pressupõe uma espécie de amnésia coletiva das transgressões cometidas pelas forças do estado. Além disso, ao incrementar o esquecimento oficial (anistia para vítimas e algozes da ditadura), a Lei no 6.683 também estabeleceu uma escala de valores no discurso da memória. As memórias da resistência foram relegadas ao fundo do porão da história, enquanto a história oficial da ditadura continuou sendo validada pela anistia. A lei compelia as vítimas a abdicar de seu direito à memória em nome da conciliação nacional.

A Lei da Anistia continua sendo considerada válida ainda hoje, apesar das diferentes medidas legais e simbólicas que foram implementadas a partir da presidência de Fernando Henrique Cardoso para conferir justiça às vítimas da ditadura e aos seus familiares.

Vemos que, apesar de medidas como a criação de uma Comissão Nacional da Verdade em 2011, o princípio da "reconciliação nacional" que permeia a Lei da Anistia continua tendo pertinência hoje em dia. Durante o estabelecimento da Comissão Nacional da Verdade, a presidente Dilma Rousseff, uma ex-militante da oposição durante a ditadura, assim como vários outros membros do governo responsáveis pela criação da comissão, repetiram enfaticamente que esta não teria poderes para julgar pessoas envolvidas com crimes de direitos humanos durante a ditadura. ${ }^{12}$

De certa forma, então, o Brasil é um paradoxo da justiça de transição. Ainda que o país tenha o maior programa de reparações depois da Segunda Guerra Mundial (Abrão e Torelly, 2012) e que, segundo Paulo Abrão, esse programa tenha aberto as portas a várias outras medidas de justiça de transição, ainda não foram tomados passos legais - ou seja, julgamentos - daqueles envolvidos em abusos durante a ditadura militar. E foi somente em anos recentes que se implementaram medidas de reparação simbólicas, tais como o estabelecimento da Comissão da Verdade, das Caravanas da Anistia e do Espaço da Memória, entre outros.

${ }^{12}$ Em uma exceção a esta postura em 2008, o então ministro da justiça Tarso Genro sugeriu que a Lei da Anistia não devia incluir o crime de tortura. As forças armadas reagirem contundentemente ao pronunciamento de Genro, que se viu obrigado a defender a instituição militar brasileira (Sikkink, 2011, p. 158). 
"O condomínio" ecoa os princípios de reconciliação nacional expressos na Lei da Anistia de 1979 e durante o processo de transição democrática. O conto de Veríssimo enfoca João, um ex-militante de esquerda que no momento do conto, ou seja, da "abertura democrática", se muda para um luxuoso e recém-construído condomínio fechado. Um dia ele se depara com o homem que o torturou no elevador. Sérgio, ${ }^{13} \mathrm{o}$ torturador, também vive no mesmo edifício e os filhos de ambos são melhores amigos. João confronta seu algoz numa reunião de condomínio. E Sérgio indica que também se lembra de haver torturado João, mas argumenta que, já que "tudo aconteceu há tanto tempo", "[e]ssas coisas não têm mais importância" (Veríssimo, 1982, p. 71). Os argumentos de Sérgio repetem a lógica da Lei da Anistia, que, de certa forma, impôs um prazo de validade sobre memórias das vítimas do regime militar. As palavras de Sérgio insinuam que nem as suas ações nem as experiências de João têm relevância na atualidade. $\mathrm{O}$ passado não é propriamente negado, mas caduca, perdendo significância. Nesse contexto, medidas de reparação são obsoletas. ${ }^{14}$

É significativo que João não se lembre nem do seu codinome nem do codinome de seu verdugo. Essa lacuna denota a dificuldade de processar o trauma em um contexto que desencoraja o trabalho da memória.

O crítico literário Jaime Ginzburg observa que "João tem abaladas sua memória, sua autoconsciência e sua relação com os outros. [...] A persistência vã em lembrar o codinome dele (de Sérgio) sinaliza a enorme dificuldade, alargada pela insistência de rever a cena dolorosa (da tortura)" (Ginzburg, 2010, p. 141). Como sugere Rebecca Atencio, em comunicação pessoal, o fato de João esquecer os nomes - mesmo que sejam apodos - indica a supressão tanto das memórias pessoais como das coletivas. A amnésia também aponta ao trauma infringido pela tortura. Para Elaine Scarry (1987), a tortura pressupõe a dissolução da vivência do sujeito, incluindo a linguagem que este/a usa para criar significado e entender seu mundo. Ao silenciar as memórias do/a torturado/a, essa capacidade linguística se vê anulada de novo. João

\footnotetext{
${ }^{13}$ O nome pode ser lido como uma alusão a Sérgio Paranhos Fleury (1933-79), o chefe do DOPS de São Paulo.

${ }^{14}$ Esta posição muda em anos posteriores, quando o governo brasileiro, começando com Fernando Henrique Cardoso, implementa várias medidas de reparação para as vítimas do terrorismo de estado.
} 
sofre das sequelas dessa experiência. Ele é atormentado pela dúvida de haver ou não delatado seus companheiros de militância: "Por mais de um ano depois de ser solto João não conseguia dormir. De noite chorava no colo de Sandra. [...] Não denunciei ninguém. Me quebraram mas não denunciei ninguém" (Veríssimo, 1982, p. 63, grifo no original). Ele insiste que não traiu ninguém, pelo menos não conscientemente (Veríssimo, 1982, p. 72). Apesar do seu sucesso profissional e de uma vida aparentemente exitosa, os fantasmas do passado continuam a atormentar o protagonista.

As memórias reprimidas/incompletas de João encontram um paralelo no modus operandi da distensão política orquestrada pelo regime militar. O silêncio imposto pelo estado a respeito dos abusos de direitos humanos cometidos durante a ditadura não somente invalidou as experiências, e portanto as memórias individuais das vítimas do regime, mas também impossibilitou o trabalho coletivo da memória em se tratando da violência cometida pelos agentes do estado. ${ }^{15}$

Sandra, a esposa de João, e que também militou na oposição, demonstra como essa postura é internalizada. Quando João conta para ela que se deparou com seu torturador no elevador, Sandra não entende por que seu marido está tão agitado. Em vez disso, ela quer falar sobre as cortinas e os móveis que eles têm que comprar para o novo apartamento. As memórias de Sandra são substituídas pelas preocupações do aqui e agora, preocupações estas que se centram no consumo. Enquanto as recordações de João parecem não ter lugar na realidade da distensão, as memórias - ainda que parciais - de Sérgio são uma espécie de capital que permite que o ex-torturador se reinvente como um bem-sucedido homem de negócios. Seu conhecimento agora é usado em uma empresa de segurança privada que protege a classe média e alta de uma nova ameaça: a violência das classes pobres. Sérgio oferece os serviços de sua empresa aos condôminos.

Um dos elementos da justiça de transição é a reforma institucional e o afastamento de perpetradores de cargos públicos (Abrão e Torelly, 2012). O negócio de Sérgio indica as possíveis consequências da falta de justiça de transição, nesse caso a continuação da violência por parte de agentes de estado, mas agora de forma extraoficial. Os antigos agentes

${ }^{15}$ Como com outras medidas de reparação, o processo de memória coletiva eventualmente toma lugar. Uma das primeiras manifestações deste processo é a publicação em 1985 de Brasil nunca mais. Como indicado no artigo, mais recentemente se criam museus, monumentos, e em 2011 se estabelece a Comissão Nacional da Verdade. 
de estado agem dentro do setor privado, mas usam as mesmas técnicas brutais da repressão (vigilância, tortura, assassinatos extrajudiciais).

A segurança privada aponta a duas facetas da cidadania diferenciada. Em primeiro lugar, esse tipo de medida conota um contexto socioeconômico onde predomina a disparidade. A diferenciação social, por sua vez, fomenta a criminalidade ou pelo menos a ideia que esta é uma ameaça onipresente. O condomínio no conto de Veríssimo, chamado "Sunset Palace" ("Um prêmio dourado para quem subiu na vida", Veríssimo, 1982, p. 64), fica ao lado de uma encosta onde residem membros de uma comunidade de baixa renda. Em contraste ao edifício luxuoso, a encosta está cheia de casebres que, segundo os residentes do Sunset Palace, devem ser removidos pela prefeitura num futuro não muito distante (ou pelo menos é isso que os condôminos esperam). O conto mostra como o direito à habitação é infringido pela falta de moradia adequada para aqueles que não têm meios socioeconômicos. Em segundo lugar, a remoção forçada também demonstra que ao mesmo tempo que os condôminos querem proteger os seus lares a qualquer custo, eles não aceitam que os moradores da comunidade tenham o mesmo direito. Para os residentes do Sunset Palace, qualquer meio - incluindo a justiça extraoficial e a destruição de lares alheios deve ser usado para resguardar a (sua) propriedade.

Um dos condôminos, Miranda, descrito como pai dedicado de duas filhas adolescentes, declara que sempre apoiou o Esquadrão da Morte (Veríssimo, 1982, p. 68). O aval de Miranda a esse tipo de organização não somente alude ao seu possível apoio à violência de estado durante a ditadura mas também conota seu apoio ao uso de violência oficial e extraoficial contra aqueles que Miranda acredita que estão ameaçando seu patrimônio, entre eles, os moradores da favela ao lado.

Como Miranda, a maioria dos residentes do Sunset Palace acha que os residentes da comunidade pobre são um perigo não somente ao seu patrimônio material mas também à sua integridade física e, de certa forma, ao seu status social. Entre outras coisas, eles temem que as crianças da comunidade na encosta invadam a piscina do edifício. Os moradores da comunidade são vistos como "bandidos", "vagabundos", "marginais". Essa criminalização dos pobres implica que eles perderam o seu "direito a ter direitos" (Arendt, 1951). Ou seja, eles não são vistos como cidadãos completos da nação. 
A Declaração Universal dos Direitos Humanos (1948) estipula não somente que esses direitos são universais, mas também que eles são indivisíveis: "Todos têm direito aos direitos professados nesta Declaração, sem distinção de qualquer tipo" (artigo 2, ver Piovesan, 2010). Em outras palavras, os direitos enunciados na Declaração são implicitamente codependentes para serem efetuados. Mas, como observa o diretório da Unesco em Brasília, no Brasil a realidade é outra. Conforme o site da instituição, no país "não há o entendimento expresso da universalidade e indivisibilidade dos direitos civis, políticos, sociais, econômicos e culturais" (Unesco, [s.d.]). Ressalte-se que a falta de direitos socioeconômicos implica a deficiência de outros direitos. $\mathrm{O}$ relatório da Anistia Internacional de 2012 para o Brasil cita, por exemplo, a prevalência da violência policial em comunidades de baixa renda. Uma das consequências dessas agressões é que tais comunidades também têm dificuldade em obter outros direitos fundamentais da cidadania, tais como educação e acesso à saúde.

Voltando à correlação entre o uso de segurança pública e a cidadania diferenciada, o emprego de aparelhos de segurança privada também demonstra a deficiência nas instituições de segurança pública (polícia, tribunais). Nesse contexto, a segurança e a justiça em geral são acessíveis principalmente àqueles que têm os meios econômicos adequados. Em "O condomínio", a implementação de um sistema de segurança privado é uma consequência da falta de justiça de transição que erode a confiança do público nas instituições legais (Sikkink e Walling, 2007, p. 441). Kathryn Sikkink observa que o Brasil tem apresentado piores índices de violações dos direitos humanos depois da transição democrática (Sikkink, 2011, p. 158). Sikkink atribui esse problema em parte à cultura de impunidade em relação aos crimes cometidos pela última ditadura militar.

No conto de Veríssimo, a maioria dos habitantes do Sunset Palace apoiam medidas extralegais para punir aos supostos transgressores. Um deles, Pires, proclama: “Eu acho que a coisa está chegando num ponto em que a gente tem que reagir no pau. Tem que matar meia dúzia em praça pública que aí o resto sossega. Esse negócio de direitos humanos é muito bonitinho, mas em país desenvolvido. Aqui não. Aqui é nós ou eles" (Veríssimo, 1982, p. 67). A declaração de Pires estabelece uma dicotomia entre "nós" (os habitantes do Sunset Palace) e "eles" (os moradores da comunidade vizinha) que evoca a diferenciação criada 
pelas autoridades militares para justificar a repressão de dissidentes políticos. O símile é repetido por outros condôminos. Um deles, o senhor Leiva, compara os vizinhos indesejados aos "comunistas" perseguidos pela ditadura. $\mathrm{O}$ apoio que Miranda expressa pelos esquadrões da morte e as posturas de Pires e do senhor Leiva propõem que os "direitos" são uma prerrogativa dos cidadãos de "bem", ou seja, aqueles que pertencem a certo estrato socioeconômico (Caldeira, 2000). Essa lógica justifica a violação dos direitos humanos de sujeitos que não se encaixam nos parâmetros da sociedade dominante. As atitudes dos residentes do Sunset Palace também recordam medidas como o AI-2 (que anulou a divisão entre o poder executivo e o judiciário) e o AI-5, durante a ditadura. Essas medidas tinham como propósito justamente a erosão dos direitos civis e políticos dos cidadãos. Mais especificamente, o artigo 4 do AI-5 permitiu que se cassassem os direitos políticos de cidadãos individuais e de políticos por até 10 anos. Essa providência, em conjunto com a anulação do habeas corpus (também determinado pelo AI-5), criou a paradoxal categoria de cidadãos sem cidadania ao abolir dois direitos fundamentais: representação legal e política.

Paradoxalmente a ditadura justificou as violações de direitos civis e políticos, alegando a necessidade de se respeitar a "autêntica ordem democrática, baseada na liberdade, no respeito à dignidade da pessoa humana, no combate à subversão e às ideologias contrárias às tradições de nosso povo" (AI-5). Essa introdução ao AI-5 emprega a terminologia democrática e dos direitos humanos para justificar o estado de exceção declarado pelo regime militar (Agamben, 2005). No período pós-transicional, uma justificativa semelhante é empregada (ainda que não de forma oficial) para proteger os direitos socioeconômicos das classes abonadas.

Enquanto que os residentes do condomínio no conto de Veríssimo criticam o conceito de direitos humanos para as camadas pobres, eles demandam de forma enfática seus direitos à propriedade, à segurança, ao lazer. Ecoando a retórica do regime militar, Pires justifica sua descrença nos direitos humanos com o argumento de que ele tem o direito de defender o seu patrimônio, ou seja, os seus direitos humanos. Pires afirma: "Eu defendo o meu patrimônio. Trabalhei por ele, não tirei de ninguém, tenho direito, é meu e vagabundo nenhum vai botar a mão" (Veríssimo, 1982, p. 68). Para resguardar seu privilégio, ele não vê problema em infringir o direito fundamental de todos os seres 
humanos, o "direito à vida, liberdade, e bem-estar pessoal" (Declaração Universal dos Direitos Humanos).

"O condomínio" exemplifica dois tipos de conflitos. Por um lado, o conto retrata a crise decorrente das desigualdades socioeconômicas. Por outro, aborda a tensão resultante da coexistência forçada de vítimas e algozes durante a transição democrática. Essa tensão é exacerbada pela impossibilidade de processar as memórias dos crimes cometidos durante o regime na esfera pública. O Sunset Palace é um lugar onde as memórias conflitivas de João e de Sérgio coincidem. Ao final, João aceita que suas memórias sejam silenciadas e se submete à ordem imposta por Sérgio. Sua aquiescência sugere que ele, ao final, se converte à ideologia da cidadania diferenciada (incluindo dos direitos à memória diferenciados). O conto termina com o protagonista reconhecendo que, apesar do seu passado de militante, ele agora é parte do status quo. O passado já não tem importância. João vê seus vizinhos na encosta do morro e tenta "discernir os seus rostos mas não enxergava a expressão de ninguém. Procurou uma maneira de mostrar que estava daquele lado do muro mas na verdade não estava, estava do lado deles. Codinome... Mas não havia maneira. Quando começou a escurecer, deixaram a piscina e entraram no palácio" (Veríssimo, 1982, p. 72). A incapacidade de João de discernir e "identificar-se" com seus vizinhos pobres conota a percepção do protagonista de que eles são, ao fim e ao cabo, uma massa anônima e, de certa forma, ameaçante.

\section{A mancha}

Publicado em 2003 pela Companhia das Letras como parte da coleção Vozes do golpe, A mancha conta a história de Rogério, um exprisioneiro e exilado político. A novela começa após o retorno do protagonista do exílio. Depois da sua volta, Rogério "enriquece". $\mathrm{O}$ verbo intransitivo insinua que isso se deu de forma quase involuntária. Mas a novela desmente essa percepção. Rogério está obcecado ("como uma causa", Veríssimo, 2004, p. 71) pela ideia de prosperar cada vez mais. Ele compra prédios decrépitos, os renova e os vende por um lucro considerável: "Compro coisas passadas e transformo em coisas novas. Ou destruo e faço outras" (Veríssimo, 2004, p. 35). Sua compulsão de destruir ou renovar edifícios velhos sugere que ele tem que superar um passado traumático. A atividade de 
Rogério pode ser lida como uma metáfora do processo transicional brasileiro que, até recentemente, favoreceu medidas econômicas de reparação sobre procedimentos simbólicos e/ou legais. Mas, como indica o título da novela, o passado permanece de forma residual, uma mancha que é um memento.

Enquanto "O condomínio" aborda o momento da abertura democrática, A mancha alude ao Brasil contemporâneo, com seus condomínios fechados horizontais - em vez de verticais - onde vive a classe média alta e as elites. Esses segmentos sociais, assim como os residentes do Sunset Palace, continuam a estar preocupados com o problema real e imaginado da criminalidade. O texto também faz referência à realidade política do momento, em que os ex-militantes de esquerda estão no poder. $\mathrm{O}$ preço que pagam por esse posicionamento são concessões ao sistema socioeconômico contra o qual lutaram. O cunhado reacionário de Rogério, Léo, afirma que não há nada mais "de direita que um esquerdista que enriqueceu" (Veríssimo, 2004, p. 40). O comentário pode ser lido como uma crítica ao então presidente Fernando Henrique Cardoso, ou a membros de esquerda da elite política que se beneficiaram das reparações econômicas oferecidas pelo governo de FHC.

Um dia Rogério encontra mais um prédio em ruínas. Ao entrar em um dos cômodos, o protagonista acredita reconhecer o lugar onde fora torturado durante a ditadura. Trata-se de uma sala vazia, com carpete barato e paredes descascadas. No carpete, Rogério vê uma mancha na forma do continente australiano. $\mathrm{O}$ protagonista acredita que a marca foi feita com o seu sangue, que pingou no chão quando ele recebeu um soco no nariz durante o seu interrogatório.

A mancha retrata as memórias da prisão e tortura de Rogério e justapõe essas recordações à sua vida presente. Ele é casado, tem uma filha e um cunhado que se declara orgulhoso de ser reacionário. Durante a narrativa, Rogério oscila entre querer resgatar as suas memórias, o seu passado, renovando o edifício e seu desejo de esquecerse dessa parte da sua vida (o que significaria demolir o prédio e vender o terreno). Tal conflito alude ao dilema do período pós-transicional: “ir em frente" e ignorar o passado, supostamente no nome de uma "reconciliação nacional" ou lidar com o passado para exorcizar os fantasmas da violência repressiva. $O$ dilema reflete a crença que a justiça de transição e o reestabelecimento da democracia são 
incompatíveis (O'Donnell, 1986). Segundo Sikkink, os estudos sobre as transições democráticas na América Latina nas décadas de 80 e 90 sugerem que medidas de justiça de transição poderiam ser uma ameaça às novas (e supostamente frágeis) democracias. No entanto, contrariamente a essa suposição, para Sikkink (2011), a justiça de transição pode fortalecer o sistema democrático.

Essa opinião está expressa também no preâmbulo do Programa Nacional de Direitos Humanos, que assevera que somente através do conhecimento abrangente sobre os crimes cometidos pelo regime militar será possível estabelecer "dispositivos seguros e um amplo compromisso consensual - entre todos os brasileiros - para que tais violações não se repitam nunca mais" (PNDH-3, Preâmbulo). Mas, demonstrando os paradoxos da construção da memória sobre o regime militar no país, o documento ao mesmo tempo delineia mecanismos para promover a recuperação dessas memórias (incluindo a criação da Comissão Nacional da Verdade) e deixa de lado toda medida judicial para atender aos crimes contra os direitos humanos cometidos pelo governo militar.

Como se sugere anteriormente, no Brasil, processos contra agentes do estado envolvidos em abusos aos direitos humanos ainda não são considerados viáveis (ou mesmo desejáveis). Até membros da Comissão Nacional da Verdade não se manifestam a favor de tais procedimentos legais. Patrick Wilcken (2012) aponta que, ao contrário de países como a Argentina e o Chile, que iniciaram processos contra membros das juntas militares (mesmo que esses processos tenham enfrentado problemas), o Brasil não somente não tomou esta medida mas mandou advogados do governo para defender na sua interpretação mais ampla a Lei da Anistia de 1979 na Suprema Corte, no Ministério da Defesa e para representar o Brasil quando este foi julgado pela Corte Interamericana de Direitos Humanos pela desaparição de 60 guerrilheiros no começo dos anos 70.16 Em 2010 o Supremo Tribunal Federal e o Ministério da Defesa julgaram que a Lei da Anistia continuava a ser constitucional. $O$ então ministro da Justiça, Cézar Peluso, aprovou a decisão ao dizer que o Brasil tinha tomado o "caminho da concórdia" em vez do da vingança ao lidar com seu passado ditatorial (Rangel, 2013, p. 78).

\footnotetext{
${ }^{16}$ Em 2010 a Corte Interamericana de Direitos Humanos declarou que a Lei da Anistia de 1979 impedia a investigação e a punição de crimes contra os direitos humanos e que, portanto, tal lei violava a Convenção Interamericana de Direitos Humanos.
} 
Para o protagonista de A mancha, preservar o edifício onde ele acredita ter sido torturado significa transformá-lo em uma espécie de memorial. Ao transformar a ruína em algo que celebra sua experiência e a memória desta, Rogério pensa que também estará honrando seus ideais e as memórias de todos aqueles que lutaram por esses mesmos ideais. Dessa forma, Rogério se transformaria no que a crítica Elizabeth Jelin chama de "empresários da memória", "atores que, de certa forma, lutam por definir e classificar as experiências de períodos de guerra, violência política, terrorismo de estado" (Jelin et al., 2003, p. 3). Para o protagonista, o edifício/memorial implica um reconhecimento de que "alguma coisa aconteceu. Ao país. A toda uma geração" (Veríssimo, 2004, p. 48).

Por um lado, o desejo de Rogério de transformar o prédio dilapidado em um memorial alude à diretiva 24 do Programa Nacional de Direitos Humanos, que estipula como um de seus objetivos a criação e manutenção de "museus, memoriais e centros de documentação sobre a resistência à ditadura" (PNDH-3, 2010 p. 176). Para isto, o PNDH dita que se disponibilizem meios econômicos para fomentar tais iniciativas (ponto A do Objetivo Estratégico I).

Por outro lado, o dilema de Rogério sobre se deve ou não preservar a ruína do passado reflete a demanda de conciliação (em vez de "vingança") no período pós-transicional, e, neste contexto, a continuidade de medidas legais tomadas durante o regime militar, como a Lei da Anistia de 1979. De certa forma, essa continuação põe em cheque a premissa básica da diretiva 24 do PNDH-3, a "Preservação da memória histórica e a construção pública da verdade" (PNDH-3, 2010, p. 175) ao promover a memória seletiva (ou seja, parcial) dos crimes contra os direitos humanos cometidos durante a ditadura.

Assim, a destruição do edifício permitiria ao protagonista de $A$ mancha esquecer, deixar o passado no passado e, nas palavras de sua esposa, Alice, se "lembrar do presente". Um presente de condomínios fechados e onde prevalece uma paz artificial entre ex-antagonistas políticos. Quando Rogério conta a Alice sua descoberta - a mancha que viu no carpete do velho edifício - ela pede ao marido que não diga nada para a filha, a fim de não estragar a harmonia familiar. Para o protagonista, esse pedido equivale à exigência de que ele ignore o seu passado e as experiências traumáticas deste. Alice acredita que essas experiências contaminam o presente, ameaçando transformar a Rogério e ao núcleo familiar em uma ruína, espelho do edifício decrépito. 
Ao tentar escavar no passado e entender o seu legado no presente, Rogério se depara com uma espécie de amnésia coletiva. Uma senhora que mora perto do prédio responde às perguntas dele sobre os antigos inquilinos dizendo: "Anos 70, meu filho. Quem é que se lembra dos anos 70? Eu não lembro mais nada" (Veríssimo, 2004, p. 23). É significativo que os únicos traços que permanecem dos antigos arrendatários, antigos documentos de aluguel, estão guardados em velhas caixas de biscoitos. O passado é contido dentro do espaço privado, doméstico, para ser revisitado individualmente - não coletivamente. Ao compensar os parentes de pessoas mortas e desaparecidas durante a ditadura, a Lei no 9.140 ao mesmo tempo reconhece e silencia esses crimes. Os direitos humanos são transformados em compensação monetária que deve indenizar a dor da perda. O estado, em outras palavras, se vê absolvido da culpa das transgressões que foram cometidas durante o regime militar. Sua responsabilidade é limitada a alguns cidadãos privados, não ao corpo social. O artigo 3 da Lei no 9.140 põe o ônus da prova do desaparecimento/morte de um ente familiar pelo estado nas mãos desses cidadãos privados, os familiares da vítima (Cano e Ferreira, 2006, p. 138). Ou seja, o trabalho da memória é relegado a indivíduos que buscam resgatar/manter viva a lembrança dos seus entes queridos. A sociedade não tem um papel definido nesse processo. Em outras palavras, a memória é transferida da esfera pública ao âmbito privado. A memória individual prevalece sobre a coletiva. Rogério chama essa transferência de "paz artificial", pois somente através dessa manipulação podem os inimigos de antanho conviver e até mesmo estabelecer laços de família - como, por exemplo, no caso de Rogério e de seu cunhado.

Como várias outras narrativas latino-americanas que abordam a ditadura militar e seu espólio, A mancha emprega a ruína como uma alegoria de um passado traumático que continua a assombrar o presente (Avelar, 1999). Idelber Avelar propõe que as ruínas alegóricas desse tipo de textos se referem tanto à destruição das utopias de esquerda durante os regimes militares e seus resíduos - entre eles a lógica capitalista (ou neoliberal) que foi implementada de forma direta ou indireta por estes governos autoritários. A mancha insinua que no Brasil pós-transicional já não há lugar para projetos sociopolíticos de uma esquerda idealista, já que esta agora é parte da lógica dominante - a do mercado. Tampouco 
há espaço para as memórias dessas utopias ou da sua destruição violenta pelo terrorismo de estado. Rubinho, um ex-colega de cela de Rogério, observa: "De tudo aquilo o que ficou foi a autopiedade. [...] Nada foi conquistado, nada foi purgado. Só nos quebraram" (Veríssimo, 2004, p. 33). A única coisa que sobrou dos ideais de Rogério e de Rubinho são ruínas, prédios decrépitos, e um silêncio incômodo.

Ruínas são uma alegoria tanto da ditadura quanto da pós-ditadura porque elas são "espaços dinâmicos, atravessados por diferentes narrativas culturais, palimpsestos sobre os quais as memórias e histórias são escritas e reescritas" (Lazzara e Unruh, 2009, p. 3). Ou seja, ruínas, mas também espaços da memória como memoriais e monumentos - tais como os descritos no começo deste ensaio - podem expor os diferentes discursos sobre a violência, a perda, a dor, o trauma que perseguem as vítimas do terrorismo de estado. Ao mesmo tempo, esses lugares estejam eles intactos ou em escombros - também contêm o reverso dessas narrativas: as histórias de "heroísmo" e de redenção nacional que são contadas pelos apologistas dos regimes autoritários.

A mancha contrasta as ruínas do passado com as novas construções do presente. A trama enfoca dois espaços: o prédio dilapidado, que, como vimos, representa a memória incômoda do passado ditatorial, e o luxuoso condomínio fechado onde Léo, o cunhado de Rogério, vive. Esse local representa a nova ordem social, econômica e política. Os contrastes entre os dois espaços denotam tanto casualidade quanto continuidade. As ruínas que Rogério destrói dão lugar a novos, faustuosos condomínios. Nesse contexto, deve-se observar que o protagonista é uma espécie de animal de carniça - ele esquadrinha os jornais procurando possíveis oportunidades na seção de óbitos, falências, despejos e outras notícias que tragam indícios de problemas financeiros ou de tragédia pessoal (Veríssimo, 2004, p. 9). Seu modus operandi sugere uma ética do oportunismo que transforma sujeitos humanos em uma espécie de dejeto reciclável (Bauman, 2004).

O contraste entre edifícios decrépitos e os condomínios fechados da elite também conota um tipo de palimpsesto entre uma narrativa que fala sobre a derrota e que supõe um esquecimento dessa derrota e o discurso do "sucesso". Este último também pressupõe dois tipos de amnésia. Por um lado, $A$ mancha aborda o silêncio/esquecimento sobre as experiências daqueles que foram perseguidos durante o regime militar. Por outro lado, a novela de Veríssimo fala das memórias 
saudosistas e idealizadas daqueles que apoiaram a ditadura. Neste caso, o passado é reescrito como uma narrativa de redenção (Stern, 2006).

Não é por coincidência que os condôminos amigos de Léo pertençam a uma direita reacionária. Além de Léo, somos apresentados a Cerqueira, ${ }^{17}$ um homem de negócios aposentado que declara orgulhosamente que ele "[e]ra de direita e se orgulhava disso. Marchara pelo Brasil em 64 e marcharia de novo pelos mesmos ideais. E mais. Achava que a história ainda faria justiça à revolução e ao regime militar, que tinham livrado o Brasil do comunismo e da anarquia e modernizado o país" (Veríssimo, 2004, p. 39). Na opinião de Cerqueira, os militares estavam defendendo a liberdade em 1964 (Veríssimo, 2004, p. 40). Suas palavras nos revelam a prevalência dos ideais de direita que foram o combustível do golpe. A declaração soberba de Cerqueira - em comparação com a tensão sentida por Rogério e Rubinho em relação ao seu passado - indica que para ele a memória do passado ditatorial não é motivo de vergonha e sim de nostalgia e de orgulho. Cerqueira, ao contrário de Rogério, que termina por relegar suas recordações ao silêncio, proclama que a lembrança da ditadura deve ser resgatada do opróbrio e exaltada. Temos aqui a representação dos direitos diferenciados da memória. Enquanto Rogério se vê forçado a esquecer, Cerqueira aclama as suas recordações e as de uma narrativa de "redenção" de forma pública.

Contrariamente a Cerqueira, Rogério decide deixar o passado para lá, enterrando-o no detrito do prédio que ele por fim resolve demolir. Ele se muda ao mesmo condomínio de Léo, tornando-se assim vizinho de Cerqueira. O protagonista aceita a "paz artificial" da nova ordem política e econômica - da qual, ao fim e a cabo, ele se beneficia.

Veríssimo configura os condomínios fechados como uma alegoria do Brasil pós-transicional. Esses lugares representam a nova ordem social, construída em parte em cima do silêncio em torno das violações dos direitos humanos durante o governo militar, silêncio este que fomenta uma cultura de conciliação e a "paz artificial" decorrente desta. Os condomínios fechados também simbolizam as divisões socioeconômicas do Brasil contemporâneo. Do lado de fora dos muros da comunidade

\footnotetext{
${ }^{17}$ Os personagens de Léo e Cerqueira podem ser lidos como alusões a Léo Frederico Cinelle, o chefe do Departamento de Triagem durante a ofensiva do Araguaia, e o Major Nilton Cerqueira, que também participou dessa mesma operação e que foi responsável pela morte de Carlos Lamarca e do seu companheiro, José Campos Barreto, também conhecido como Zequinha.
} 
fechada estão aqueles que - aos olhos da classe média e alta representam um perigo à integridade física e material destes segmentos. A separação física deste exterior ameaçador permite uma paz artificial àqueles que podem pagar por ela. Como em "O condomínio", em A mancha, os residentes também estabelecem suas próprias leis. Os seguranças da firma privada contratados pelos condôminos têm ordens de atirar em qualquer pessoa que não pareça pertencer à seleta comunidade de moradores e dos seus convidados. Assim como "O condomínio", A mancha sugere que os direitos humanos de uns existem à custa dos direitos de outros, dos que não se enquadram dentro de certos padrões socioeconômicos (Caldeira, 2000). Dito de outra forma, os direitos econômicos (da propriedade, por exemplo) de uma minoria prevalecem sobre os direitos sociais e civis de uma maioria.

Gostaria de encerrar este ensaio com uma breve observação sobre o significado dos memoriais hoje em dia no Brasil. Desde 2003, ano em que foi publicada A mancha, o estado brasileiro tomou várias medidas simbólicas que reconhecem e, de certa forma, tentam reparar as violações aos direitos humanos cometidas pela ditadura militar. Em 2008, a Comissão da Anistia estabeleceu as Caravanas da Anistia. As Caravanas da Anistia têm como objetivo informar o público brasileiro, em especial a geração que nasceu depois da abertura, sobre o regime militar e suas transgressões. Também em 2008 o estado de São Paulo decidiu estabelecer o Memorial da Resistência, no lugar que antes abrigava o Memorial da Liberdade (e, antes disso, o DOI-CODI de São Paulo). O Memorial da Resistência foi inaugurado em janeiro de 2009. E, como mencionado no começo deste ensaio, em novembro de 2011 a presidente Dilma Vana Rousseff inaugurou a Comissão Nacional da Verdade. A Comissão, que continua vigente no momento de redação deste artigo, tem o encargo de investigar crimes contra os direitos humanos que ocorreram entre 1946 e 1988. No entanto, a Comissão não tem incumbência legal. As pessoas que forem identificadas como perpetradores de tais crimes não serão julgadas em tribunais de justiça.

Essas são apenas algumas iniciativas que, em anos recentes, têm tentado lidar com o legado da repressão efetuada pelo regime militar no país. Podemos dizer que hoje em dia a memória deste período já não é suprimida, relegada aos "porões" da memória nacional em nome de uma conciliação entre diferentes setores/atores sociais e políticos. 
Como indica a estudiosa norte-americana Rebecca Atencio (2014), o Brasil iniciou um novo ciclo da memória. As recordações sancionadas da ditadura são mais uma capa de significados no discurso mnemônico sobre a ditadura. O Dopinha de Porto Alegre, um lugar que foi uma residência, depois um centro clandestino de tortura, agora possivelmente se transformará em memorial, ganhando assim um novo significado sem que o antigo se apague das suas paredes. Não obstante, esse reconhecimento do papel do estado na violação dos direitos humanos coexiste com uma falta de (re)conhecimento sobre o período ditatorial. É o que vemos na "invisibilidade" do Memorial aos Mortos e Desaparecidos em Porto Alegre.

Uma imagem que talvez encapsule essa dialética entre visibilidade e invisibilidade é o desenho de um "desaparecido" em uma pedra na praça da Alfândega, em pleno centro de Porto Alegre (figura 4). O rosto desconhecido, anônimo, por um lado evoca a repressão e seus métodos e, por outro, faz desaparecer a pessoa retratada novamente. Fica a pergunta: quem é ele/ela? A foto também nos lembra dos "desaparecidos" do Brasil contemporâneo. Quando minha amiga e eu visitamos esse lugar no nosso tour dos memoriais da ditadura em Porto Alegre, a imagem era quase invisível no meio dos carrinhos dos moradores de rua e dos mendigos que transitam pelo centro da capital gaúcha e de todos os centros metropolitanos brasileiros. 


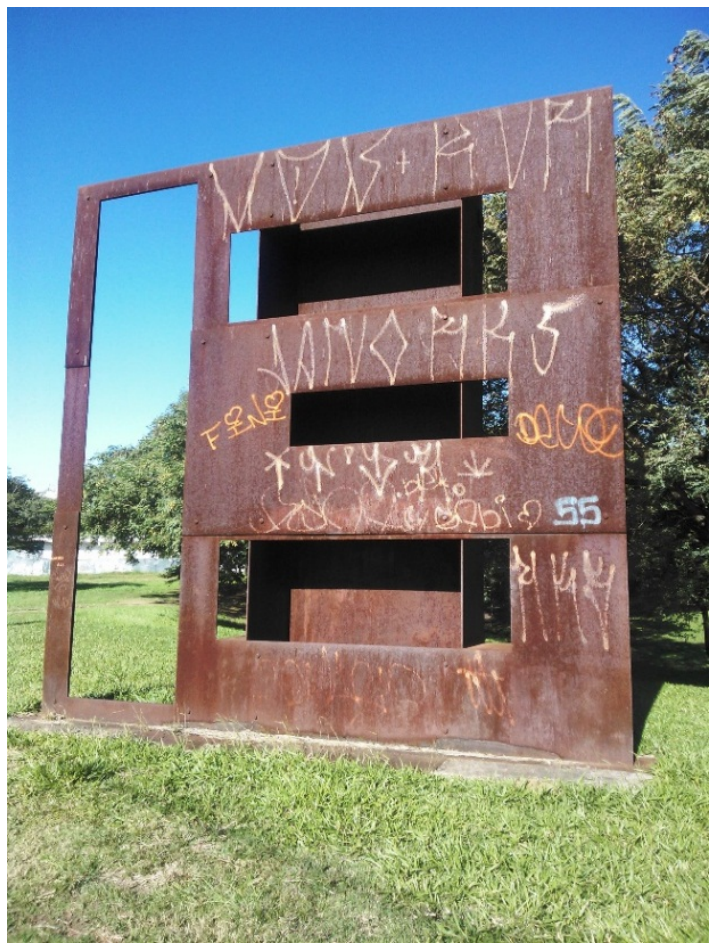

Fig. 1: Parte dianteira do Memorial aos Mortos e Desaparecidos, Porto Alegre, 2013.

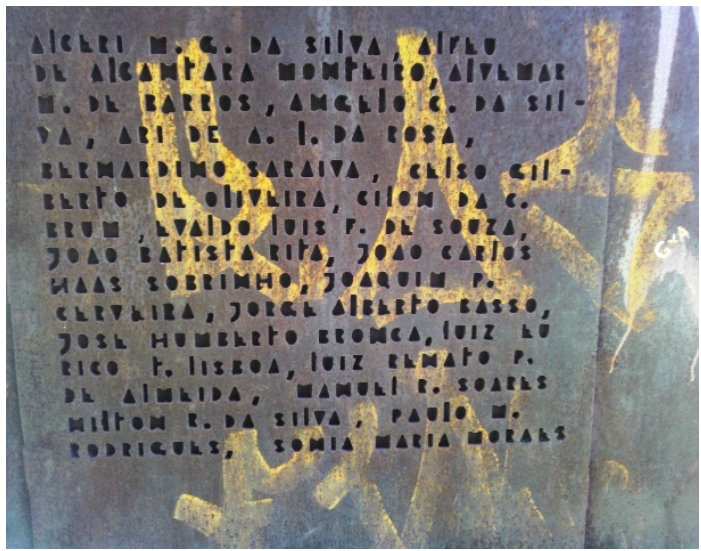

Fig. 2: Parte de atrás do Memorial aos Mortos e Desaparecidos, Porto Alegre (nomes dos desaparecidos), 2013. 


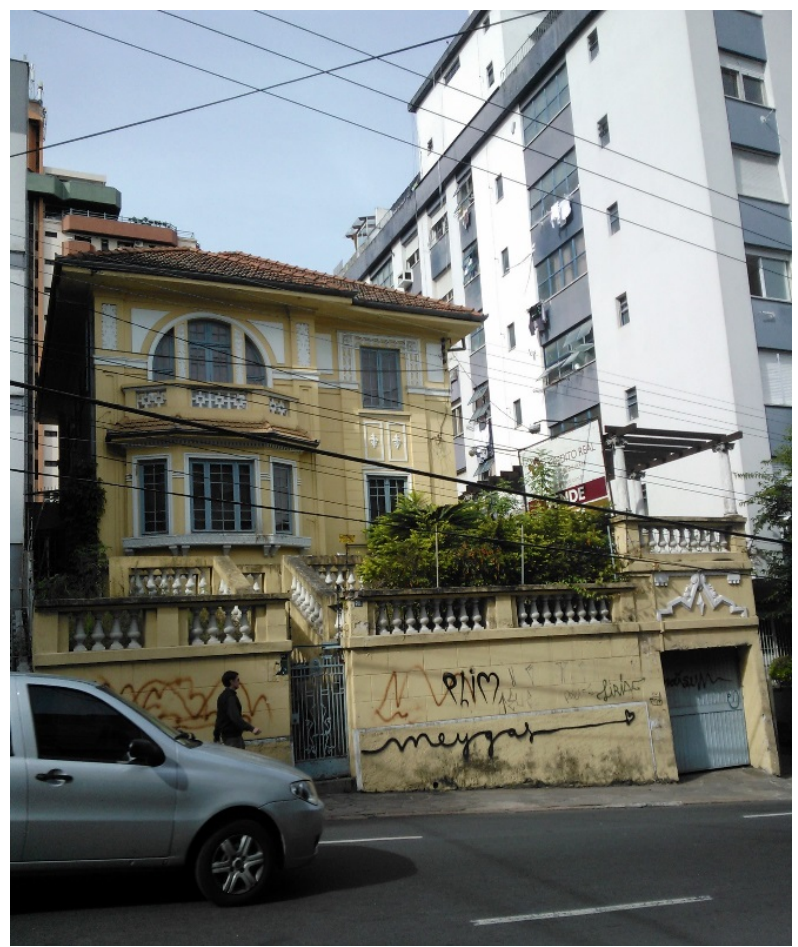

Fig. 3: Rua Santo Antônio, 600 (Dopinha), Porto Alegre, 2013. 


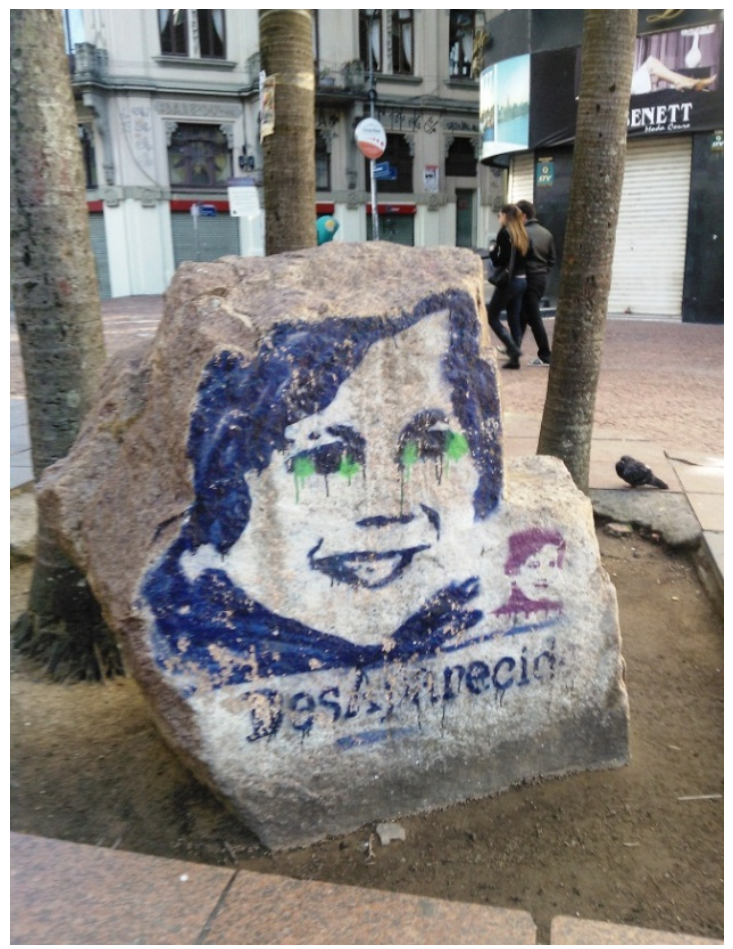

Figura 4: Praça da Alfândega, Porto Alegre, 2013.

\section{Referências}

ABRÃO, Paulo; TORELLY, Marcelo D. (2012). Resistance to change: Brazil's persistent amnesty and its alternatives for truth and justice. In: LESSA, Francesca; PAYNE, Leigh A. (Eds.). Amnesty in the age of human rights accountability: comparative and international perspectives. Cambridge: Cambridge University Press.

AGAMBEN, Giorgio (2005). State of exception. Chicago: University of Chicago Press.

ARENDT, Hannah (1951). The origins of totalitarianism. New York: Harcourt, Brace and Co.

ATENCIO, Rebecca (2014). Memory's Turn: reckoning with dictatorship in Brazil. Madison: University of Wisconsin Press. 
AVELAR, Idelber (1999). The untimely present: postdictatorial Latin American fiction and the task of mourning. Durham: Duke University Press.

BAUMAN, Zygmunt (2004). Wasted lives: modernity and its outcasts. Oxford: Polity.

BRASIL (1979). Lei 6.683, de 28 de agosto. Concede anistia e dá outras providências. Disponível em: http://www.planalto.gov.br/ccivil_03/leis/L6683.htm. Acesso em: 10 mar. 2014.

CALDEIRA, Teresa P. R. (2000). City of walls: crime, segregation, and citizenship in São Paulo. Berkeley: University of California Press.

CANO, Ignacio; FERREIRA, Patricia S. (2006). The reparations programs in Brazil. In: GREIFF, Pablo (Ed.). Handbook of reparations. Oxford: Oxford University Press.

COMITE CARLOS DE RÉ. Disponível em: http://comitedaverdadeportoalegre.wordpress.com. Acesso em: 20 mar. 2013.

DECLARAÇÃO UNIVERSAL DOS DIREITOS HUMANOS. Disponível em: http://portal.mj.gov.br/sedh/ct/legis_intern/ddh_bib_inter_universal.htm. Acesso em: 05 mar. 2013.

GINZBURG, Jaime (2010). Escritas da tortura. In: TELES, Edson; SAFATLE, Vladimir (orgs.). O que resta da ditadura: a exceção brasileira. São Paulo: Boitempo.

HITE, Katherine (2011). Politics and the art of commemoration: memorials to struggle in Latin America and Spain. New York: Routledge.

HOLSTON, James (2008). Insurgent citizenship: disjunctions of democracy and modernity in Brazil. Princeton: Princeton University Press.

JELIN, Elizabeth; REIN, Judy; GODOY-ANATIVIA, Marcial (eds.) (2003). State repression and the labors of memory. Minneapolis, University of Minnesota Press.

LAZZARA, Michael J.; UNRUH, Vicky (2009). Introduction: telling ruins. In: LAZZARA, Michael; UNRUH, Vicky (Eds.). Telling ruins in Latin America. New York: Palgrave Macmillan.

MARSIGLIA, Ivan (2012). E o direito à memória bateu à porta. O Estado de $S$. Paulo, São Paulo, 26 ago. Caderno Aliás. Disponível em: http://www.estadao.com.br/noticias/impresso,e-o-direito-a-memoria-bateu-aporta,921878,0.htm. Acesso em: 10 mar. 2014. 
MEZAROBBA, Glenda (2010). Between reparations, half truths and impunity: the difficult break with the legacy of the dictatorship in Brazil. Sur - Revista internacional de direitos humanos, São Paulo, v. 7, n. 13, p. 7-25.

MITCHELL, José (2007). Segredos à direita e à esquerda na ditadura militar. Porto Alegre: RBS.

O'DONNELL, Guilermo et al. (1986). Transitions from authoritarian rule. Baltimore: Johns Hopkins University Press.

PIOVESAN, Flávia (2010). Direito internacional dos direitos humanos e lei de anistia: o caso brasileiro. In: TELES, Edson; SAFATLE, Vladimir (orgs.). O que resta da ditadura: a exceção brasileira. São Paulo: Boitempo.

PROGRAMA NACIONAL DOS DIREITOS HUMANOS (PDH) (2010). Disponível em: http://portal.mj.gov.br/sedh/pndh3/index.html. Acesso em: 09 mar. 2014.

RANGEL, Carolina (2013). Vingança é o objetivo. Veja, São Paulo, 29 mai. p. 7678.

SIKKINK, Kathryn (2011). The justice cascade: how human rights prosecutions are changing world politics. New York: W. W. Norton \& Co.

SIKKINK, Kathryn; WALLING, Carrie B. (2007). The impact of human rights trials in Latin America. Journal of peace research, Oslo, v. 44, n. 4, p. 427-445.

UNESCO Office in Brasilia. Human rights in Brazil. Disponível em: http://www.unesco.org/new/en/brasilia/social-and-human-sciences/humanrights. Acesso em: 10 mar. 2014.

SCARRY, Elaine (1987). The body in pain: the making and unmaking of the world. New York: Oxford University Press.

STERN, Steve J. (2006). Battling for hearts and minds: memory struggles in Pinochet's Chile. Durham: Duke University Press

TEITEL, Ruti G. (2000). Transitional justice. Oxford: Oxford University Press.

VERÍSSIMO, Luis Fernando (1982). O condomínio. In: Outras do analista de Bagé. Porto Alegre: L\&PM. (2004). A mancha. São Paulo: Companhia das Letras.

WILCKEN, Patrick (2012). The reckoning. Investigating torture in Brazil. New left review, London, n. 73, p. 63-78.

Recebido em dezembro de 2013.

Aprovado em fevereiro de 2014. 


\section{resumolabstract}

\section{Memórias manchadas e ruínas memoriais em $A$ mancha e "O condomínio", de Luis Fernando Veríssimo}

Leila Lehnen

Este artigo propõe que locais esquizofrênicos da memória - locais construídos como palimpsestos de várias (e muitas vezes contraditórias) versões do passado - estão conectados com o que o antropólogo James Holston (2008) denomina de "cidadania diferenciada". O artigo estabelece uma analogia entre os direitos diferenciados da memória e as disposições constitucionais que legalizam as diferenças sociais e civis e que, segundo Holston, são uma das características da cidadania diferenciada.

Palavras-chave: ditadura, memória, cidadania, Luis Fernando Veríssimo.

Stained memories and ruined memorials in $A$ mancha and "O condomínio", de Luis Fernando Veríssimo

\section{Leila Lehnen}

This article proposes that what it calls "schizophrenic memory sites" - places that are constructed as palimpsests of various (and, at times, contradictory) versions of the past - are connected with what anthropologist James Hoslton (2008) denominates "differentiated citizenship". The article establishes an analogy between differentiated memory rights and the constitutional measures that legalize social and civil differences and that, according to Holston, make up differentiated citizenship.

Keywords: dictatorship, memory, citizenship, Luis Fernando Veríssimo. 